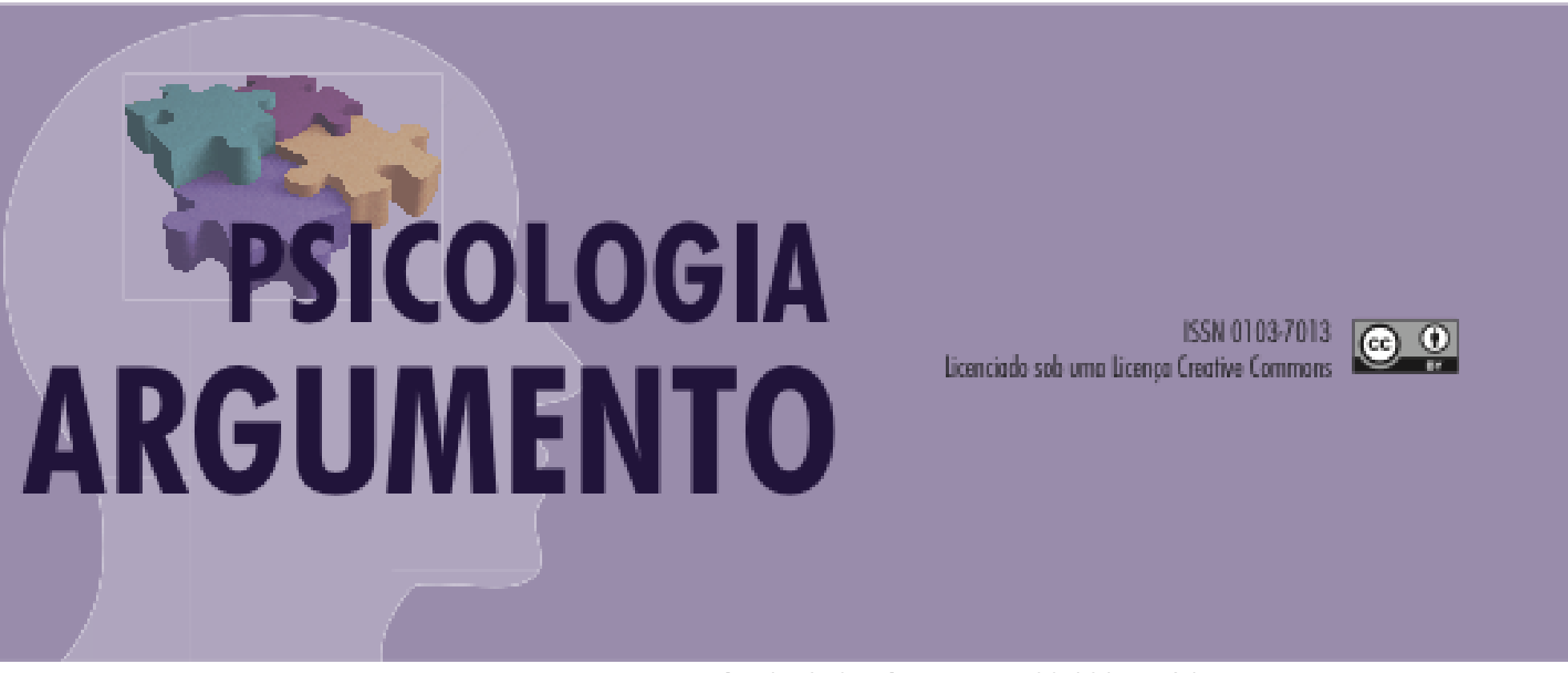

doi: 10.7213/psicol.argum.33.080.REO01

\title{
Resenha
}

\section{Crise Suicida: Avaliação e manejo}

\author{
BOTEGA, Neury Jose. Crise Suicida: Avaliação e manejo. Porto \\ Alegre: Artmed, 2015.
}

\section{Por Cloves Antonio de Amissis Amorim [a]}

O suicídio é um problema imemorial, complexo e desafiador. Tanto em função do so-frimento individual quanto familiar e coletivo; aliando-se às perdas pessoais, materiais e econômicas que pode causar; sendo assim no entendimento de Bertolote (2012) tornou-se um grave problema da saúde pública. O mesmo autor também afirma que "o suicídio é a pior de todas as tragédias humanas. Não apenas representa a culminância de um sofrimento insuportável para o indivíduo, mas também significa uma dor perpétua e um questionamento torturante, infindável, para os que ficam" (2012, p. 7).

Como docente da disciplina de Tanatologia nos últimos 15 anos no curso de Psicologia da PUCPR (Pontifícia Universidade Católica do Paraná), tenho buscado busco a atualização da literatura sobre o comportamento suicida; sendo que, desde a publicação de Werlang e Botega (2004), havia uma lacuna no campo de estudos em relação às obras publicadas com dados e características da nossa população. É verdade que as clássicas obras Il Suicidio de Monti e D’Agostino (2012) na Itália, e a obra Guía de Práctica Clínica de Prevención y Tratamiento de La Conducta Suicida do Ministério de Sanidad, Política Social e Igualdad (2012) na Espanha, apresentam uma síntese de dados publicados pela Organização Mundial de Saúde e sugestões de intervenção.

Crise Suicida é uma obra composta por introdução, 13 treze capítulos e nove apêndices, e ainda uma extensa bibliografia no item "Referências" (460 documentos). Trata-se de uma obra fundamental para os que desejam se atualizar e desenvolver repertório profissional para a avaliação e o manejo do comportamento suicida. $\mathrm{Na}$ 
introdução o autor destaca que apesar de sua formação de psiquiatra ter sido bastante influenciada pela perspectiva psicanalítica, sua experiência acrescentou algo do pragmatismo cognitivo-comportamental e os tempos atuais o colocaram nos caminhos da psicologia humanista. Além de apresentar sua prática clínica em hospital universitário e consultório, apresentam a proposta de pre-venção do suicídio. Ao enfatizar a avaliação do risco de suicídio como um campo inter-subjetivo, afirma:

Em geral, lutamos pela vida e pensamos na morte de forma genérica e abstrata, como algo distante. O paciente suicida é ameaçador, fere devoções e expectativas. Ao trazer a morte para mais perto, ele desafia subterfúgios existenciais de quem o atende. Por isso, vários mecanismos de defesa psicológica são ativados e se combinam com a finalidade de evitar a percepção desse drama humano e proteger-nos. Aí entram os preconceitos, as crenças, a repulsa automática e a noção que construímos a respeito do que deve permane-cer fora de nossa responsabilidade profissional.

Tudo isso pode enrijecer nossa conduta frente aos pacientes, com o abandono de uma postura acolhedora e com o embasamento da percepção do raciocínio clinico. [...] (p. 13)

No capítulo 01 - Atitudes, o autor descreve a atitude frente ao suicídio na antiguidade Greco-romana (tolerância), passa à Idade Média (condenação) e chega a Idade Moderna (dilema) concluindo que as concepções e atitudes em relação ao suicídio no ocidente cul-minam como um problema de saúde pública. Apresenta o quadro 1.3 - Crenças errôneas em relação ao suicídio: 1) se eu perguntar sobre suicídio, poderei induzir o paciente a isso; 2) ele está ameaçando se suicidar apenas para manipular; 3) quem quer se matar, se mata mesmo; 4) o suicídio só ocorre quando há uma doença mental; 5) no lugar dele, eu tam-bém me mataria; 6) quem se mata é bem diferente de quem apenas tenta e 7) uma vez suicida, sempre suicida. (p. 29 - 30). O capítulo 01 apresenta o apêndice 01 sobre o suicí-dio em diferentes religiões e culturas. E o apêndice 02 sobre comportamento suicida: ati-tudes da enfermagem.

Dados epidemiológicos, frequências, variações por sexo e idade, meios de suicídio e ideação suicida compõe o capítulo 02 sobre magnitude. Neste capítulo, a apêndice 01 aborda um olhar crítico sobre as estatísticas de suicídio. $\mathrm{O}$ apêndice 02 mostra o mapa do suicídio no município de São Paulo. O apêndice 03 apresenta o suicídio em povos indíge-nas.

No capítulo 03 - Entendimentos, são apresentadas as teorias biológicas e psicológicas, bem como as contribuições de Edwin Shneidman e Durkheim, e ainda a compreensão do filósofo e escritor francês Albert Camus.

Os fatores de risco para o suicídio é o tema do capítulo 04. São apresentados fatores sociodemográficos, transtornos mentais, fatores psicossociais e outros. O autor também lista fatores predisponentes e precipitantes. Aponta os fatores de proteção contra o suicí-dio: personalidade e estilo cognitivo, estrutura familiar, fatores socioculturais e outros. Destaca-se ainda neste capítulo que entre as ocupações, médicos e dentistas destacam-se por apresentarem taxas de suicídio 5 e 2 vezes maiores, respectivamente, do que a popula-ção em geral (p. 94). Ainda no capítulo 04 o apêndice 01 aborda o paradoxo do gênero onde destaca que homens usam métodos mais violentos e mais letais em suas tentativas de suicídio, principalmente armas de fogo. Alerta ainda que AA a menor ocorrência de suicídio entre mulheres pode ser atribuída à baixa prevalência de alcoolismo, à religiosidade, às atitudes mais flexíveis e ao desempenho dos papéis sociais que lhe são peculiares. E no apêndice 02 aborda as tentativas de suicídio no HC - Unicamp.

O capítulo 05 aborda transtornos mentais. Na figura 5.1 - transtornos mentais associ-ados ao suicídio, baseada em Bertolote e Fleischmann (2002), apresenta que na autópsia psicológica de 15629 suicídios na população geral, $36 \%$ apresentavam transtornos do humor, $22 \%$ transtornos relacionado ao abuso de substâncias, $12 \%$ transtornos da persona-lidade e $11 \%$ esquizofrenia. Na página 127 propõe o exame do estado mental. E na página 131 apresenta a escala hospitalar de ansiedade e depressão, seguida da página 133, onde se encontra um exemplo do miniexame do estado mental (mini-mental).

No capítulo 06 o foco é avaliação, apontando o tipo de risco, possibilidade de ocor-rência e os aspectos clínicos mais relevantes. A figura 6.3 lista os estados afetivos que se associam a um maior risco de suicídio - Os 
Ds: Dor psíquica, Desespero, Desesperança, Desamparo, Depressão, Dependência Química, Delírio e Delirium. Um dos aspectos anali-sados em profundidade é a intencionalidade suicida: ideia de morte, ideação suicida e plano suicida. O capítulo é encerrado com a formulação do risco de suicídio. No apêndice se encontra "o risco de suicídio entre adolescentes" e ainda um anexo com um roteiro para avaliação do risco de suicídio (p. 160).

Primeiras providências é tema do capítulo 07. Apresenta-se um plano terapêutico quando se atende alguém que tem um risco agudo. A primeira estratégia é manter o paci-ente seguro, seja no pronto socorro, em domicílio ou durante a internação psiquiátrica. O autor enfatiza a importância do esclarecimento e apoio aos familiares e conclui o capítulo com a proposta de monitorar e obter colaboração.

O capítulo 08 se ocupa da Psicoterapia de Crise. Caracteriza-se as ações do terapeuta e apresenta-se o referencial teórico e os princípios da psicoterapia de crise. Este capítulo permite o link para o capítulo 09 - O cuidar. Na página 196 o autor afirma que "o profissi-onal que atende uma pessoa em crise suicida deveria ter a capacidade de exercer essa função" e lista alguns atributos pessoais desejados para o cuidador: empatia, espontanei-dade, calma confiante e limites. Trata com especial atenção o fenômeno da contratransfe-rência, passando a considerar as armadilhas do narcisismo e conclui com a necessidade do cuidador se cuidar.

Mantendo o paciente estável é o título do capítulo 10. Inicialmente aborda a depressão e o transtorno bipolar, em seguida discorre sobre personalidade, mecanismos de defesa e coping. Conclui o capítulo com uma profunda análise sobre os fatores relacionados à falta de adesão ao tratamento.

No capítulo 11 - "Após um suicídio", - de acordo com o autor para cada suicídio es-tima-se que entre 05 e 10 pessoas sejam profundamente afetadas. (p. 226). Coque, raiva, culpa, agitação e desemparo são analisados. O papel do profissional de saúde e o impacto nos mesmos encerra o capítulo. No capítulo 12 são listados e analisados os aspectos legais destacando o sigilo, a relação contratual e internação involuntária.

O capítulo 13 - Prevenção é um dos pontos altos da obra. No início do capítulo, no quadro 13.1 são apresentados itens contidos nos planos nacionais de prevenção de suicí-dio. No quadro seguinte, 13.2 são encontrados os marcos recentes na trajetória de preven-ção do suicídio no Brasil, chama atenção que foi somente em 2006 que o Ministério da Saúde elaborou as diretrizes nacionais para prevenção do suicídio. Nas modalidades de prevenção, são apresentados os níveis: Universal, seletiva e indicada, com a população alvo e exemplos de ações. Conclui-se o capítulo com a apresentação dos entraves. O apên-dice deste capítulo lista os sites de interesse, os manuais que estão disponíveis e a apresen-tação do link das Diretrizes Nacionais para a prevenção do suicídio.

Merece destaque a qualidade e a quantidade de referências, representando um verda-deiro estudo do tipo estado da arte. Ampla cobertura nacional e internacional. Verdadei-ramente estamos diante de um livro clássico com leitura mais que indicada para todos que se interessem pelo dilema humano do suicídio.

\section{Referências}

Bertolote, J. M. (2012). 0 suicídio e sua prevenção. São Paulo: Editore da Unesp.

Ministerio de Sanidadad, Politica Social e Igualdad. (2012). Guía de Practica Clínica de Prevención y Tratamiento de La Conducta Suicida. Madrid: Agencia de Evaluación de Tecnologias Sanitarias de Galicia, avalia-t.

Monti, M. R. e D’Agostino, A. (2012) Il Suicidio. Roma: Carocci editore

[a] Psicólogo, Especialista em Bioética e em Cuidados paliativos, Mestre em educação e doutorando em Educação. Docente do Curso de Psicologia da Pontifícia Universidade Católica do Paraná. 